\title{
EDUCAÇÃO ESPECIAL NO MUNICÍPIO DE MACEIÓ/ALAGOAS: A FRAGILIDADE DAS POLÍTICAS PÚBLICAS
}

\author{
Marily Oliveira Barbosa ${ }^{1}$ \\ Neiza de Lourdes Frederico Fumes ${ }^{2}$ (1)
}

RESUMO: Esse estudo visou analisar o processo de constituição da educação especial em Maceió, procurando apreciar os principais prescritores das práticas escolares envolvendo o Público Alvo da Educação Especial (PAEE). Essa é uma pesquisa documental que abrangeu o Plano Municipal de Educação, a Resolução do Conselho Municipal de Educação e o Guia de Educação Especial para a inclusão na rede municipal de Maceió. Os resultados mostraram que o município busca seguir as prescriçôes por meio dos seus dispositivos legais, embora haja entraves que dificultem a materialização das ações prescritas.

Palavras-chave: Educação especial. Educação. Políticas públicas.

\section{Special education in the municipality of Maceio, Alagoas, Brazil: the fragility of public policies}

ABSTRACT: This study aims to analyze the process of special education's constitution in Maceió, focusing on appreciating the main prescriptions of school practices involving the Students of Special Education (SSE). It is a documental research that covered the Municipal Education Plan, the Resolution of the Municipal

${ }^{1}$ Centro Universitário Maurício de Nassau - Maceió (AL), Brasil.

E-mail: marilyufal@gmail.com

${ }^{2}$ Universidade Federal de Alagoas - Maceió (AL), Brasil. E-mail: neizaf@yahoo.com DOI: 10.1590/CC0101-32622018198135 
Council of Education and the Special Education Guidelines for inclusion in the network of Maceió city. The results showed that the municipality seeks to follow the prescriptions through its legal documents, although there are obstacles that make difficult to materialize the prescribed actions.

Keywords: Special education. Education. Public policy.

\section{INTRODUÇÃO}

A

educação especial constitui-se como área do conhecimento que abrange o Público-Alvo da Educação Especial (PAEE) que, no âmbito brasileiro, é formado pelas pessoas com deficiência, transtorno do espectro autista (TEA) e com superdotação/altas habilidades. A mesma norma legal que define esse público é a Política Nacional de Educação Especial na Perspectiva da Educação Inclusiva (PNEEPEI), que

direciona suas açôes para o atendimento às especificidades desses estudantes no processo educacional e, no âmbito de uma atuação mais ampla na escola, orienta a organização de redes de apoio, a formação continuada, a identificação de recursos, serviços e o desenvolvimento de práticas colaborativas (BRASIL, 2008, p. 11).

Recentemente, a Lei Brasileira de Inclusão veio reafirmar que a educação é um direito da pessoa com deficiência, ao mesmo tempo em que lhe assegura um "sistema educacional inclusivo em todos os níveis e aprendizado ao longo de toda a vida” (BRASIL, 2015, p. 1). Apesar disso, é preciso ter claro que a constituição desse sistema ainda está em processo, havendo a necessidade de superar preconceitos e atrasos históricos em relação a essa população (e outros grupos historicamente excluídos), que produziram níveis elevados de analfabetismo, evasão e fracasso escolar. "Nenhum aluno deveria precisar ser aprovado em um teste ou esperar resultados de pesquisa favoráveis para viver e aprender como membros re- 
gulares da vida escolar e comunitária" (KARAGIANNIS; STAINBACK; STAINBACK, 1999, p. 27).

Com isso, parece-nos oportuno recuperar a posição de Saviani (2011) de que não é possível pensar em educação sem que haja a presença e a participação de todos os indivíduos na escola regular. Para tanto, é preponderante pensar numa escola para todos, que garanta o acesso aos conhecimentos acumulados sistematicamente pela humanidade e oportunize o desenvolvimento humano. Nesse sentido, falar em educação inclusiva implica garantir a efetivação do acesso, da permanência, da participação e da aprendizagem acadêmica (BRASIL, 2015).

Em virtude de políticas públicas desencadeadas, principalmente, nos governos de Luís Inácio Lula da Silva (2003-2011) e Dilma Rousseff (2011-2016), houve ampliação do número de matrículas do PAEE, com destaque positivo àquelas realizadas em escolas regulares, que superaram as realizadas em classes e escolas especiais como, ainda, um paulatino avanço nos níveis de escolarização desses estudantes (BRASIL, 2016b).

O Censo Escolar de 2016 revelou, ainda, que 82\% do PAEE matriculado encontravam-se em escolas regulares e que quase $58 \%$ das escolas brasileiras tinham em seu corpo discente estudantes PAEE (BRASIL, 2016b). Não obstante a esses avanços, o caminho para a escolarização de qualidade do PAEE ainda é longo e demanda políticas públicas consistentes e continuadas, o que não se tem visto nas atuais políticas do governo federal e que podem ser prejudicadas seriamente a partir da aprovação da Emenda Constitucional no 95/2016, que estabeleceu o limite de gastos públicos para os próximos 20 anos no país (BRASIL, 2016b).

No que diz respeito aos mecanismos para viabilizar a permanência e a participação desses estudantes nas escolas regulares, tem sido assegurado minimamente o Atendimento Educacional Especializado (AEE) e, em alguns casos, a presença de um profissional de apoio escolar (BRASIL, 2011; 2015).

O serviço do AEE é "compreendido como o conjunto de atividades, recursos de acessibilidade e pedagógicos organizados institucional e continuamente" (BRASIL, 2011). Esse atendimento, segundo o prescrito no conjunto de normas legais, objetiva contribuir na escolarização do PAEE, sendo preconizado que esteja integrado à proposta pedagógica da escola. 
Para atuar no AEE, “o professor deve ter formação inicial que o habilite para o exercício da docência e formação específica para a Educação Especial" (BRASIL, 2009, p. 3). Entretanto, o que se tem visto é que cada município flexibiliza a exigência da formação desse profissional e sua atuação (BARROS, 2009; BARBOSA, 2014; FONSECA; BRIDI, 2016). Essa realidade envolvendo a diversidade de perfis do professor que atua no AEE e a multiplicidade de atribuições desse profissional evidencia a necessidade de aprofundamento das discussóes acerca da sua formação e função.

Outro ponto nevrálgico da efetivação da política da área da educaçáo especial diz respeito ao profissional de apoio escolar, cuja atuação ainda não está claramente definida no Brasil, bem como ainda não há prescrição de suas ações nas legislações (BRASIL, 2015). Estudos científicos (PEREIRA, 2014; BARBOSA, 2014; FONSECA; BRIDI, 2016) mostram de forma incisiva essas confusões e indefinições.

Em 2015, a Lei Brasileira de Inclusão, no 13.146, no artigo $3^{\circ}$ XIII, define como profissional de apoio escolar a

pessoa que exerce atividades de alimentação, higiene e locomoçáo do estudante com deficiência e atua em todas as atividades escolares nas quais se fizer necessária, em todos os níveis e modalidades de ensino, em instituiçóes públicas e privadas, excluídas as técnicas ou os procedimentos identificados com profissóes legalmente estabelecidas (BRASIL, 2015).

Com isso, retira das atribuiçóes desse profissional aquelas que envolvem procedimentos específicos de outras profissóes.

No governo atual (Michel Temer, a partir 2016), há um silenciamento sobre a situação dos diversos programas da área da educação eEspecial, bem como a ausência de novas proposiçóes e a redução acentuada no investimento de programas voltados para a garantia de direitos sociais. Esses fatos e as atuais diretrizes politico-econômicas colocam em cheque os direitos arduarmente conquistados e efetivados nos governos anteriores, muito embora ainda existissem críticas quanto a isso.

No entanto, é preciso investigar, de uma maneira criteriosa, a forma como tem ocorrido a materialização dessas políticas públicas nas 
estruturas municipais para melhor entender seu impacto na garantia ao direito à educação do PAEE. Esses estudos precisam ocorrer em todo o território nacional para que esse retrato consiga trazer as especificidades locais e regionais e, assim, avançar nas novas proposituras. Considerando esses aspectos, o objetivo desse artigo foi analisar o processo de constituição da educação especial em Maceió, procurando apreciar os principais prescritores das práticas escolares envolvendo o público alvo da educação especial.

\section{METODOLOGIA}

Essa pesquisa é do tipo documental, sendo incumbência do pesquisador analisar os tipos de documento adequados às suas finalidades para, assim, selecionar aqueles de maior interesse e utilizá-los. Chizzotti (2005, p. 18) salienta que "quem inicia uma pesquisa não pode dispensar as informações documentadas", visto que por meio dos documentos há possibilidade de conhecer a situação histórica e atual sobre o problema que se pretende investigar.

Os estudos de Garcia $(2016 ; 2017)$ e suas discussóes relacionadas à Política de Educação Especial na perspectiva da Educação Inclusiva na realidade brasileira colaboraram na problematização e discussão crítica dos documentos analisados do município de Maceió.

Para essa pesquisa, os documentos utilizados foram: o Plano Municipal de Educação referente ao período de 2015 a 2025 (MACEIÓ, 2015), a Resolução no 01, de 2016, do Conselho Municipal de Educação de Maceió (MACEIÓ, 2016a) e o Guia de Educação Especial para a Inclusão na Rede Municipal de Maceió (MACEIÓ, 2016b).

A análise de conteúdo, do tipo temático (BARDIN, 2009), foi empregue e ocorreu em três etapas: pré-análise; exploração dos dispositivos legais elencados; e interpretaçáo, buscando observar os pontos relacionados aos objetivos do estudo.

A análise dos documentos considerou as seguintes temáticas:

- configuração da Educação Especial no município de Maceió/ Alagoas

- $\quad$ prescritores da Educação Especial no município de Maceió/ Alagoas. 


\section{RESULTADOS E DISCUSSÃO}

\section{CONFIGURAÇÃO DA EDUCAÇÃO ESPECIAL NO MUNICÍPIO DE MACEIÓ/ALAGOAS}

A cidade de Maceió é capital do Estado de Alagoas, sendo um de seus 102 municípios e localiza-se na Regiáo Nordeste do Brasil (MACEIÓ, 2015), com população estimada de 1.021.709 habitantes (ATLAS BRASIL, 2013). O Índice de Desenvolvimento Humano Municipal (IDHM) de Maceió, em 2010, era de 0,721, próximo ao IDHM da Unidade Federativa, de 0,727. Esse número coloca Maceió na faixa de Desenvolvimento Humano Alto (IDHM entre 0,700 e 0,799) (ATLAS BRASIL, 2013).

Em nível educacional, conta com uma Secretaria Municipal de Educação (SEMED), onde estão vinculadas 130 escolas públicas municipais em atividade, distribuídas em oito regióes administrativas (MACEIÓ, 2015). Essas instituiçóes oferecem educação infantil, ensino fundamental e educação de jovens e adultos (EJA) para 49.622 estudantes regularmente matriculados, dos quais 2.321 estão na educação especial no formato de dupla matrícula, referentes à escola regular e ao serviço do AEE (INEP, 2015).

O Instituto Nacional de Estudos e Pesquisas Educacionais Anísio Teixeira (INEP) revelou que os estudantes dos anos iniciais do ensino fundamental da rede pública de Maceió tiveram nota média de 4.4 no Índice de Desenvolvimento da Educação Básica ${ }^{1}$, (IDEB) enquanto a média nacional foi de 5,5 (INEP, 2015).

Apesar dos investimentos próprios e em cooperação técnica com o [Ministério da Educação] MEC, a realidade da [Rede Municipal de Educação] RME de Maceió se apresenta, no momento, com um quadro ainda insatisfatório no tocante aos Índices de Desenvolvimento da Educação Básica (IDEB) e a qualidade da prática pedagógica desenvolvida nas unidades escolares. Entende-se que esse desencontro pode ocorrer como consequência de aspectos, como: a) Lacunas nas formaçôes inicial e continuada dos profissionais; 
b) Falta de continuidade das ações político-administrativas das gestôes da SEMED, em função das frequentes mudanças dos dirigentes; c) Compreensão e práticas equivocadas no processo de construção da gestáo democrática; d) Inexistência de sistemáticas de monitoramento e acompanhamento técnico às açóes pedagógicas e administrativas junto às unidades escolares; e) Falta de articulaçáo entre a equipe gestora e o conselho escolar nas unidades escolares; f) Ausência de uma política de formação e de valorização dos profissionais da educação, no tocante à validação e certificação dos cursos realizados; g) Falta de uma prática institucional de apoio e articulação entre as redes públicas de ensino do município (MACEIÓ, 2015, p. 78).

No que diz respeito à educação especial, o município busca seguir o direcionamento das legislaçóes nacionais quanto aos preceitos da educação inclusiva em ambiente de escola regular para o PAEE (BRASIL, 2008; 2011; 2015).

O Censo Escolar Brasileiro de 2016 mostra que, naquele ano, no município de Maceió, não havia matriculas na educação especial na modalidade substitutiva para o PAEE, sendo que os alunos estavam matriculados em salas comuns e no AEE (BRASIL, 2016a).

A institucionalização da Educação Especial no município aconteceu tardiamente, havendo a criação do Departamento de Educação Especial (DEE) apenas na década de 1980. De um modo geral, podemos dizer que o DEE seguiu os movimentos das políticas nacionais uma vez que começou com a criação das classes especiais passando, posteriormente, para as salas de recursos e, mais recentemente, para as Salas de Recursos Multifuncionais (SRM) (MERCADO; FUMES, 2016).

Nos dias atuais, o DEE integra a Diretoria Geral de Ensino e tem como objetivo "orientar, acompanhar, oferecer apoio técnico, pedagógico e administrativo; supervisionar e fiscalizar as instituiçóes de ensino públicas, privadas, filantrópicas, confessionais e comunitárias que atendem à Educação Especial" (MACEIÓ, 2016a, p. 3).

Nas últimas duas décadas, o município aderiu aos seguintes programas propostos e subsidiados: Escola Acessível, Transporte Escolar 
Acessível, Implantação da Sala de Recursos Multifuncionais, Formação Continuada de Professores na Educação Especial, Benefício de Prestação Continuada (BPC) na Escola e Livro Acessível (BARBOSA; MELO JÚNIOR, 2017). Por outro lado, não se observa a proposição de programas/ações específicos e propostos pelo próprio município de Maceió.

Para atender a esses estudantes, os dados do DEE da SEMED apresentam o seguinte quantitativo de recursos humanos da Educação Especial: uma coordenadora, uma auxiliar administrativa, 11 técnicas pedagógicas (professoras efetivas da rede pública municipal e desviadas da função), 86 professores do AEE, cinco professores intérprete de Língua Brasileira de Sinais (Libras), e 386 profissionais de apoio escolar (ARAÚJO; FUMES, 2014; MERCADO, 2016). Muitos desses profissionais têm permanecido nos cargos em diferentes gestóes de governo (ARAÚJO; FUMES, 2014).

As técnicas pedagógicas eram responsáveis pelo acompanhamento dos professores que atuavam nas SRM (em média, cada uma acompanhava cinco escolas) e pela proposição e realização das ações de formação continuada, envolvendo os professores de Educação Especial e da sala comum, bem como os gestores (ARAÚJO, FUMES, 2014). As autoras afirmam, ainda, que esses técnicos não possuíam formação continuada específica e nem diferenciada para tal função (tinham titulação apenas de especialistas) e contavam apenas com reunióes de grupo para gerir tais atividades.

Se para as técnicas não havia formação continuada específicas, essas organizavam as formaçóes com caráter obrigatório de participação no formato quinzenal para os professores do AEE e mensal para os profissionais de apoio escolar. Essas formaçóes tratavam de assuntos relacionados às deficiências por meio de uma abordagem médica e/ou psicopedagógica. Pesquisas com os participantes apontaram para a necessidade de modificaçóes dos conteúdos e da sistemática, de modo a auxiliar na compreensão e na proposição de respostas aos desafios impostos pelo cotidiano escolar (BARROS, 2009; FUMES et al., 2014).

Quanto ao concurso para profissionais de apoio escolar, observa-se que nunca existiu para a rede municipal de Educação de Maceió, tendo havido apenas um edital, em 2008, que dispunha do cargo de 
auxiliar de sala, sendo que esses profissionais, no momento de posse, puderam optar por atuar na educação especial (MACEIÓ, 2008).

A consequência mais visível disso é que grande parte dos profissionais de apoio que atuam na rede foi contratada por meio de processos seletivos simplificados (MACEIÓ, 2015) que exigiam apenas o nível de ensino fundamental de escolarização. No entanto, a própria esfera federal ainda tem imprecisóes sobre as características e a formação desse profissional, ocasionando a publicação de diferentes notas técnicas e instrumentos legais afins (BRASIL, 2015).

Quanto à oferta do AEE, em 2015, havia 73 escolas públicas municipais que disponibilizavam o serviço, além de outras nove SRM que funcionavam por convênios/parcerias firmados com outras instituições de fins filantrópicos (MACEIÓ, 2015). Observa-se que esses convênios com instituiçôes filantrópicas foram fortalecidos e expandidos nos últimos anos.

Nomeadamente, em 2017, houve a renovação dos convênios para a realização do AEE em entidades filantrópicas de 950 estudantes do PAEE, que também estavam matriculados em escolas públicas municipais (MACEIÓ, 2017). Chama a atenção o fato de que a SEMED de Maceió tinha como discurso, à época, de que a renovação dos convênios promoveria a melhoria e a ampliação do atendimento dos estudantes do PAEE.

Entretanto, precisamos ter clareza que essa é uma tendência histórica da educação especial brasileira que, por décadas, tem injetado dinheiro e mantido interdependência com instituiçóes por um serviço que a própria educação do estado poderia assumir efetivamente (LAPLANE; CAIADO; KASSAR, 2016; GARCIA, 2017).

O município de Maceió atende 2.494 estudantes com oitenta e seis professores do AEE e atua ainda no monitoramento, orientação e oferta de formação continuada para os professores do AEE do município (MACEIÓ, 2016b). Assim, é crucial que haja um repensar para as açóes da educação especial. Segundo Garcia (2017), a atual política dessa área, na perspectiva da educação inclusiva, insere-se em um ambiente amplo (escola), que possui implicações de ordem estrutural, organizacional, recursos humanos, entre outros que, por vezes, não são cogitados nas diretrizes oficiais. Apenas configurar os serviços de AEE e a prescrição de um profissional de apoio escolar não responde à heterogeneidade das de- 
mandas dos estudantes. É preciso, também, o auxílio de profissionais da educação especial para atuar com os professores nas salas de aula dando suporte na formação e no acompanhamento aos estudantes PAEE.

\section{PRESCRITORES DA EDUCAÇAO ESPECIAL NO MUNICÍPIO DE MACEIÓ/ALAGOAS}

É preponderante conhecer os prescritores para poder analisar a forma como a educaçáo especial (EE) se materializa nas diferentes esferas governamentais. Não obstante dessa importância, é preciso não perder de vista que a maioria dos municípios brasileiros não possui um setor de EE ou um responsável pelas açôes dessa modalidade (JESUS; CAIADO; RIBEIRO, 2016). Por sua vez, Garcia (2016) discute como as políticas relacionadas à educaçáo especial tem se materializado de formas diversas nos municípios brasileiros.

No caso de Maceió, diversas dificuldades para a implementação já foram evidenciadas anteriormente, bem como a recenticidade de grande parte das proposituras. Nesse processo estáo alguns prescritores que orientam e configuram a educação do PAEE no município e que precisam ser conhecidos.

O primeiro diz respeito ao Plano Municipal de Educação (PME) referente ao período de 2015 a 2025 (MACEIÓ, 2015). Esse documento coaduna com os Planos de Educação de âmbito estadual e nacional que visam a construçáo do Sistema Nacional de Educação articulado. O PME é constituído por introdução, caracterização geral de Maceió, estrutura, metas e estratégias, além de etapas da educação básica com um diagnóstico da situação de cada uma delas no município. Há subcapítulos que explicitam sobre as modalidades e diversidades educacionais, tais como educação de jovens e adultos, educação especial, educação do campo, educação para a promoção da igualdade nas relaçóes étnico-raciais, educação ambiental e educação superior. Entre todas, a que tem menor caracterização é a educação especial. Das 127 laudas que constituem o documento, apenas duas laudas e meia são dedicadas a essa modalidade, demonstrando o descaso para essa, que deve estar presente em todas as instâncias educacionais atendidas pelo PME. As questóes 
referentes à educaçáo especial dizem respeito ao serviço do AEE e ao aumento do número de matrículas do PAEE em ambiente de escola regular.

Um documento da magnitude do PME deveria tratar com mais afinco e amplitude as questóes referentes à educação especial, visto que a modalidade não deveria se resumir apenas ao AEE e às SRM. Como bem define a PNEEPEI, é preciso também viabilizar "a organização de redes de apoio, a formação continuada, a identificação de recursos, serviços e o desenvolvimento de práticas colaborativas" (BRASIL, 2008, p. 11).

Há silêncios ensurdecedores no PME quanto às metas a ser alcançadas para os estudantes PAEE e quanto o município planeja, de forma reducionista, as questốes da educação especial. Com isso corre-se o risco de não manter marginalizado os grupos abrangidos pelo PAEE. Ademais, ao náo ser propositiva, reproduz lacunas e limitaçóes da PNEEPEI (BRASIL, 2008). Em termos da atual política, Schreiber (2017, p. 205) considera:

As políticas de Educação Especial de 'perspectiva inclusiva', ao mesmo tempo em que disseminam um discurso em defesa da matrícula de todos os alunos no ensino regular, desqualificam o trabalho pedagógico desenvolvido na classe comum, na medida em que não disponibilizam condiçóes adequadas para o oferecimento de um ensino de qualidade.

Sendo assim, as políticas públicas precisam refletir e prescrever serviços e profissionais a serem articulados com o trabalho dos professores regentes em sala comum.

A formaçáo, as condiçóes de trabalho e a precarização da atuação docente também são questôes que precisam urgentemente ser problematizadas, como também precisam de previsão orçamentária específicas. Pesquisas alagoanas (BARROS, 2009; ARAÚJO; FUMES, 2014; BARBOSA, 2014; FUMES et al., 2014; MERCADO, 2016) demonstraram que há muitas determinaçōes nos dispositivos legais que não se materializam nas práticas, fazendo-se necessário acompanhamento e auxilio para que o prescrito se torne realidade no cotidiano escolar.

No que diz respeito à valorização dos profissionais da educação, o PME deu ênfase a formaçáo inicial e continuada e o Plano de Carreira e 
Remuneração do município de Maceió. Embora, em nenhum momento, esteja claro quem são os profissionais da educação, havendo menção à luta de alguns profissionais que atuam na escola para integrar esse quadro.

No PME não há menção quanto à atuação dos profissionais da educação especial e nem a proposição de metas específicas para eles.

Há lacunas da oferta de formação continuada para os professores de sala de aula no que tange à educação especial/inclusiva (BARROS, 2009; FUMES et al., 2014; PEREIRA, 2014). É importante esclarecer que os professores regentes participam de outras açóes no âmbito da formação continuada que não abordam a temática da educação especial deixando, assim, um imenso abismo no processo de ensino dos estudantes PAEE (JESUS; CAIADO; RIBEIRO, 2016).

O PME aborda, ainda, a gestão e o financiamento explicitando a origem dos recursos financeiros da educaçáo municipal, mas náo cita as fontes do financiamento da educação especial, o que compromete a materialização de um sistema de ensino público e inclusivo.

Em inúmeros momentos de suas obras, Saviani (2014) discutiu a necessidade de ampliação de recursos orçamentários com a realização de novos cálculos e repasses financeiros para a manutenção da educação brasileira. Para o avanço das propostas e açóes na área da educação especial, é preponderante que haja mais investimentos financeiros, sem eles as prescrições se tornam metas inatingíveis.

O segundo documento analisado diz respeito à Resolução no 1 do Conselho Municipal de Educação (COMED) de Maceió, de 2016. Importante dizer que essa foi a primeira resolução da educação especial do município, tendo sido construída em audiências públicas abertas à participação popular e que veio preencher uma lacuna imensa existente. Indubitavelmente, a participação direta e efetiva da sociedade em sessóes públicas, inclusive com a presença das autoras desse estudo, deu uma maior representatividade ao documento e ouviu grupos que estão diretamente envolvidos na luta pelos direitos à educação do PAEE.

O propósito da Resolução no 1 é: "Estabelece(r) normas para a Educação Especial, na perspectiva da Educação Inclusiva, e para o Atendimento Educacional Especializado" (MACEIÓ, 2016a, p. 1). 
De forma concisa, a resolução se apoiou nos diversos dispositivos legais brasileiros e municipais sobre a educação especial. Nela é explicada sobre o DEE, sua organizaçáo, funcionamento e recursos humanos, bem como sobre o sistema educacional inclusivo, dando ênfase ao serviço do AEE e à ampliação das matrículas em escola regular retificando, ainda, quanto à participação dos estudantes em todas as disciplinas, inclusive na de Educação Física, em instituiçóes de nível público e privado (MACEIÓ, 2016a). Um avanço do documento é a menção à matrícula respeitando a idade cronológica do estudante, bem como a quantidade de estudantes PAEE em sala de aula comum.

A aprovação da Resolução no 1 contrapóe-se a uma realidade de muitos municípios brasileiros que não possuem dispositivos legais para nortear a educação especial (JESUS; CAIADO; RIBEIRO, 2016; GARCIA, 2017), o que compromete a consolidação dos direitos dos estudantes PAEE no município.

O terceiro documento analisado foi o Guia de Educação Especial para a inclusão na rede municipal de Maceió (MACEIÓ, 2016b), que possui os princípios, orientaçóes e práticas relacionadas à educação especial. Foi construído em parceria com o Ministério da Educação (MEC) e sobre a tutela do Programa das Naçóes Unidas para o Desenvolvimento (PNUD), contando com a participação dos profissionais do DEE.

O guia foi lançado em uma grande cerimônia com a participação de professores e gestores. Nomeadamente, aborda aspectos relacionados à inclusão escolar, direitos humanos, acessibilidade, marcos históricos e conceituais da educação especial e é finalizado com experiências educacionais inclusivas relatadas por três professoras do AEE do município.

Esse documento orienta as açóes dos profissionais que atuam com estudantes PAEE tendo em vista as especificidades de cada trabalho. Estudos anteriores que pesquisaram a realidade de Maceió (BARROS, 2009; BARBOSA, 2014; FUMES et al., 2014; MERCADO, 2016) encontraram resultados quanto à imprecisão da atuação dos diferentes profissionais da educação o que, por vezes, dificultava o processo de escolarização dos estudantes PAEE. Nesse sentido, o guia potencializa o fazer docente por trazer deliberaçóes para os profissionais quanto ao estabelecimento de funções na esfera educacional. 
A partir da análise desses documentos, parece apropriado trazer Saviani (2011, p. 4) que afirma que "as medidas tomadas pelo governo, ainda que partam de necessidades reais e respondam com alguma competência a essas necessidades, padecem de uma incapacidade congênita de resolvê-las". Nesse sentido, muitos dos dispositivos brasileiros, particularmente em Maceió, expóem direitos, mas não problematizam nem fornecem orientaçóes para que o prescrito se materialize no cotidiano escolar. É necessário ampliar o conhecimento dos processos da educação especial (GARCIA, 2016; 2017) com o objetivo de evitar que os movimentos específicos da área terminem sendo dirigidos a outras açóes.

\section{CONSIDERAÇÕES FINAIS}

A educação especial em Maceió tem passado por inúmeras transformaçóes ao longo dos anos, envolvendo o público de estudantes a ser atendido e os serviços ofertados.

O processo de constituição da educação especial no município proveio das pressóes sociais em relaçáo ao prescrito no âmbito nacional para os estudantes PAEE. No entanto, Maceió carece de políticas próprias quanto à educação especial, visto que as ações realizadas são pontuais, visando cumprir minimamente o proposto pelo governo federal, e essas açóes não suprem as necessidades do PAEE. Alguns municípios brasileiros têm avançado e prescrito açóes próprias, visando ampliar as açóes da área da educação especial, criando e executando outros movimentos além dos preceitos nacionais (PEREIRA, 2014; GARCIA, 2016; JESUS; CAIADO; RIBEIRO, 2016).

Factualmente, houve um aumento de matrículas desses estudantes no município, sendo necessárias ações que potencializem a permanência, a participaçáo e a aprendizagem dos conteúdos acadêmicos. É imprescindível que o município construa um olhar cauteloso quanto às parcerias com as instituiçôes especializadas, visto que essas estão ganhando notoriedade no AEE e na EJA ampliando o número de estudantes atendidos por meio de um atendimento medicalizado que vai de encontro aos preceitos da educação inclusiva. Além do mais, essas instituições não realizam diálogo com escola e/ou professores, o que dificulta ainda 
mais o processo de inclusão escolar. Historicamente, essas instituiçóes não têm cumprido seu papel com a sociedade quanto à educabilidade do PAEE (MELETTI, 2006; LAPLANE; CAIADO; KASSAR, 2016).

O município ainda tem um longo caminho a trilhar no que se relaciona à educação especial na perspectiva da educação inclusiva. É preponderante haver a criação de cargos públicos na área, bem como a ampliação dos recursos financeiros destinadas. O DEE precisa da ampliação do pessoal de recursos humanos para assim fornecer formação continuada aos professores do AEE e da sala de aula que responda aos desafios encontrados no cotidiano, bem como haja a ampliação do suporte aos educadores que atuam cotidianamente com os estudantes PAEE. Por tais fatos, urge a necessidade de um maior investimento na educação da pessoa com deficiência, juntamente a um melhor acompanhamento das políticas educacionais buscando, assim, soluçóes para os problemas e novas alternativas.

\section{REFERÊNCIAS}

ARAÚJO, L.R.; FUMES, N.L.F. A formação profissional da equipe técnica da diretoria de Educação Especial da SEMED/ Maceió/AL. In: SEMANA INTERNACIONAL DE PEDAGOGIA; ENCONTRO DE PESQUISA EM EDUCAÇÃO DE ALAGOAS, 2014, Maceió. Anais... Maceió, 2014, p. 1-14.

ATLAS BRASIL. Atlas do Desenvolvimento Humano no Brasil ano 2013. 2013. Disponível em: <http://www.atlasbrasil.org.br/2013 >. Acesso em: 20 ago. 2017.

BARBOSA, M.O. Atividade docente em Sala de Recursos Multifuncionais para educandos com Transtorno do Espectro Autista. 145f. Dissertação (Mestrado em Educação) - Universidade Federal de Alagoas, Maceió, 2014.

BARBOSA, M.O.; MELO JÚNIOR, A.L. Escolarização do Público Alvo da Educação Especial (PAEE): a realidade e o prescrito nos dispositivos legais. In: SOUZA, C.T.R.

BARBOSA, M.O.; BRIEGA, D.M. (Orgs.). Pesquisas em Educação Especial: Fios e Desafios. Curitiba: Appris, 2017. p. 95-110.

BARDIN, L. Análise de conteúdo. 4. ed. Lisboa: Ediçôes 70, 2009.

BARROS, M.L.N.L. Inclusão e formação docente: histórias de vida de professores da rede pública municipal de Maceió. 135f. Dissertação (Mestrado em Educação Brasileira) - Universidade Federal de Alagoas, Maceió, 2009. 
BRASIL. Censo Escolar 2016: notas estatísticas. Brasil, 2016a. Disponível em: <http://portal.mec.gov.br/docman/fevereiro-2017-pdf/59931-app-censoescolar-da-educacao-basica-2016-pdf-1/file>. Acesso em: 20 nov. 2017.

. Decreto no 7.611, de 17 de novembro de 2011. Dispóe sobre a educação especial, o atendimento educacional especializado e dá outras providências. Brasília: Imprensa Oficial, 2011.

. Emenda Constitucional no 95, de 15 de dezembro de 2016. Brasil, 2016b. Disponível em: <http://www.planalto.gov.br/ccivil 03/constituicao/Emendas/ Emc/emc95.htm>. Acesso em: 20 jun. 2018.

. Lei Brasileira de Inclusão da Pessoa com Deficiência no 13.146. Brasil: Presidência da República, 2015.

- Política Nacional de Educação Especial na Perspectiva da Educação Inclusiva. Brasília: Ministério da Educação/Secretaria de Educação Especial/ Imprensa Oficial, 2008.

. Resolução no 4, de 2 de outubro de 2009. Institui Diretrizes Operacionais para o Atendimento Educacional Especializado na Educação Básica, modalidade Educação Especial. Brasília: Imprensa Oficial, 2009.

CHIZZOTTI, A. Pesquisa em ciências humanas e sociais. 7. ed. São Paulo: Cortez, 2005.

FONSECA, M.; BRIDI, F.R. de S. A atuaçáo do profissional de apoio/monitor na Rede Privada de Ensino. In: REUNIÂO CIENTÍFICA REGIONAL DA ASSOCIAÇÃO NACIONAL DE PESQUISA E PÓS-GRADUAÇÃO, 11., 2016, Curitiba. Educação, Movimentos Sociais e Politicas Governamentais. Curitiba: ANPEd, 2016. p. 1-16.

FUMES, N.L.F.; CALHEIROS, D.S.; MERCADO, E.L.O.; SILVA, F.K.R.; BARBOSA, M.O.; SANTOS, S.D.G. A formação continuada de professores de salas de recursos multifuncionais do município de Maceió/AL. Teias, Rio de Janeiro, v. 15, n. 35, p. 71-87, 2014.

GARCIA, R.M.C. Disputas conservadoras na política de Educação Especial na perspectiva inclusiva. In: (Org.) Políticas de educação especial no Brasil no início do século XXI. Florianópolis: UFSC, 2017. p. 19-66.

. Educaçáo especial na perspectiva inclusiva: determinantes econômicos e políticos. Comunicaçôes, Piracicaba, v. 23, n. 3, Número Especial, p. 43-56, 2016. http://dx.doi.org/10.15600/2238-121X/comunicacoes.v23nespp7-26 
INSTITUTO NACIONAL DE ESTUDOS E PESQUISAS EDUCACIONAIS ANÍSIO TEIXEIRA (INEP). Censo escolar 2015. Brasil: INEP, 2015. Disponível em: <http://portal.inep.gov.br>. Acesso: 12 set. 2017.

JESUS, D.M.; CAIADO, K.R.M.; RIBEIRO, L.H.C. Educação Especial, políticas e contextos: o caso de Cariacica. Comunicaçôes, Piracicaba, v. 23, n. 3, Número Especial, p. 57-79, 2016. http://dx.doi.org/10.15600/2238-121X/ comunicacoes.v23nespp57-79

KARAGIANNIS, A.; STAINBACK, S.; STAINBACK, W. Fundamentos do ensino inclusivo. In: STAINBACK, S.; STAINBACK, W. (Orgs.). Inclusão: um guia para educadores. Porto Alegre: Artmed, 1999. p. 21-34.

LAPLANE, A.L.F.; CAIADO, K.R.M.; KASSAR, M.C.M. As relações públicoprivado na Educação Especial: tendências atuais no Brasil. Teias, v. 17, n. 46, p. 40-55, 2016. http://dx.doi.org/10.12957/teias.2016.25497

MACEIÓ. Conselho Municipal de Educação de Maceió. Resolução no 01/2016. Maceió: Conselho Municipal de Educação de Maceió, 2016a.

. Lei $\mathrm{n}^{\circ} 6.493$, de 23 de novembro de 2015. Aprova o Plano Municipal de Educação para o período de 2015 a 2025, e dá outras providências. Diário Oficial de Maceió, Maceió, 2015. Disponível em: <http://www.maceio.al.gov.br/ wp-content/uploads/admin/documento/2015/11/Diario Oficial $2411 \quad 15$ PDF.PARTE 01.pdf >. Acesso em: 24 nov. 2015.

- Secretaria Municipal de Administraçáo, Recursos Humanos e Patrimônio. Secretaria Municipal de Educação. Secretaria Municipal de Saúde. Edital no 01/2008. Maceió: Secretaria Municipal de Administração, Recursos Humanos e Patrimônio/Secretaria Municipal de Educação/Secretaria Municipal de Saúde, 2008. Disponível em: <https://www.pciconcursos.com.br/concurso/ prefeitura-de-maceio-al-1461-vagas $>$. Acesso em: 21 nov. 2017.

. Secretaria Municipal de Educação. Guia de educação especial para a inclusão na rede municipal de Maceió: princípios, orientaçóes e práticas. Maceió: Viva, $2016 \mathrm{~b}$.

. Secretaria Municipal de Educação. Parceria garante atenção especializada a alunos com deficiência. 2017. Disponível em: <http://www.maceio.al.gov. br/2017/04/parceria-garante-atendimento-especializado-a-alunos-comdeficiencia/>. Acesso em: 21 nov. 2017.

MELETTI, S.M.F. Educação escolar da pessoa com deficiência mental em instituiçôes de educação especial: da política à instituição concreta. 138f. Tese (Doutorado) - Universidade de São Paulo, São Paulo, 2006. 
MERCADO, E.L.O. Identidades do professor de educação especial no contexto de Maceió-Alagoas. 320f. Tese (Doutorado em Educação) - Universidade Federal de Alagoas, Maceió, 2016.

MERCADO, E.L.O; FUMES, N.L.F. A Educação Especial no município de Maceió: das classes especiais às Salas de Recursos Multifuncionais. In: CONGRESSO BRASILEIRO DE EDUCAÇÃO ESPECIAL, 7., São Carlos, 2016. Anais... São Carlos, 2016. p. 1-20.

PEREIRA, D.M. Análise dos efeitos de um plano educacional individualizado no desenvolvimento acadêmico e funcional de um aluno com transtorno do espectro do autismo. 181f. Dissertação (Mestrado em Educação) - Universidade Federal do Rio Grande do Norte, Natal, 2014.

SAVIANI, D. Da nova LDB ao FUNDEB: por uma outra política de educacional. 4. ed. Campinas: Autores Associados, 2011.

. Sistema nacional de educação e plano nacional de educação: significado, controvérsias e perspectivas. Campinas: Autores Associados, 2014.

SCHREIBER, D.V.A.F. A organização do trabalho docente na classe comum com os alunos da modalidade educação especial: controvérsias da desqualificação do trabalho pedagógico. In: GARCIA, R.M.C. (Org.) Políticas de educação especial no Brasil no início do século XXI. Florianópolis: UFSC, 2017. p. 161-210.

\section{NOTAS}

1. O IDEB é um indicador de qualidade educacional que combina informaçôes de desempenho em exames padronizados (Prova Brasil ou Saeb) — obtido pelos estudantes ao final das etapas de ensino ( $4^{a}$ e $8^{a}$ séries do ensino fundamental e $3^{a}$ série do ensino médio) - com informaçôes sobre rendimento escolar (aprovação) (INEP, 2015).

Recebido em 15 de maio de 2018.

Aprovado em 02 de agosto de 2018. 